\title{
Location and shelf mapping from OPAC search results: with reference to Wichita State University
}

\author{
Hongfei Li \\ City University of Seattle, Bellvue, Washington, USA, and \\ Sai Deng \\ Wichita State University Libraries, Wichita, Kansas, USA
}

\begin{abstract}
Purpose - The purpose of this paper is to examine dynamic mapping of holding locations to the animated maps in a library catalog which aims to resolve complex shelving situations, augment the user experience in locating library materials and enrich the Online Public Access Catalog (OPAC) by integrating external programming into the Integrated Library System (ILS).

Design/methodology/approach - Dynamic mapping displays animated direction maps for users to locate quickly the items found in the library catalog. The maps are displayed in accordance with various shelving policies. At Wichita State University Libraries, the original bibliographic data are captured from the record results page in the OPAC and transferred to a processing program residing on another server. Instead of transferring ISBN/ISSN (International Standard Book Number/ International Standard Serial Number, as practiced by some libraries) to display the Syndetic cover images, it transfers bibliographic ID and a few other fields from MARC (MAchine-Readable Cataloging) records to a processing program which queries the ILS database for extracting data needed for the dynamic map processing. The dynamic map system consists of three sections: queried data from the ILS database, programming logic, and dynamic maps.

Findings - Compared to title-level shelving map displays that have been implemented in some libraries, holding level map displays solve the problem of complex shelving situations, such as a title with multiple copies shelved in different locations and/or in different formats.

Originality/value - This project received very positive feedback from the library community and this paper will provide information to those libraries which are interested in dynamically presenting holding information in their OPAC.

Keywords Libraries, Academic libraries, United States of America, Cataloguing

Paper type Research paper

Location and shelf mapping

Received 10 October 2007

Reviewed 28 November 2007

New Library World

Vol. 109 No. 3/4, 2008

pp. 107-116

@ Emerald Group Publishing Limited

$0307-4803$

DOI $10.1108 / 03074800810857577$
\end{abstract}

The current issue and full text archive of this journal is available at www.emeraldinsight.com/03074803.htm 


\section{Introduction}

The user, the catalog, and the web environment

How can the user experience be facilitated in the discovery, locating and delivery of materials in an

Online Public Access Catalog (OPAC)? User expectation and user behaviour are influenced by their web experiences and we need to rethink our catalog in a changing network environment (Byrum, 2005b; Dempsey, 2006; Calhoun, 2006).

The legacy catalog has complicated search interfaces, and its way of providing directional information to library collections, such as explaining holdings in plain text using the "location" label and giving static floor maps, cannot keep up with the expectation of the new generation of users who grew up with the Global Positioning System (GPS) and video games.

The preference for web and search engines over the traditional library catalog is increasing according to Online Computer Library Center's (OCLC) international library research report. The report is based on surveys of users from six countries. In total, 84 percent of the respondents use search engines to begin an information search. But, only 1 percent begin a search on a library web site (DeRosa, 2005). User frustration in a library is not a new concept and some of the frustration is directly related to how to find information and locate the item. The library community has put considerable effort into improving the OPAC to meet the users' needs. Aspects of this effort are: Linking the information universe has become a trend and integrating users' search experiences has grown to be very important. Dempsey (2006) talks about "Unified discovery experience", and he thinks that the current library service is fragmented and the library catalog does not provide the same level of unified services as Google, Amazon and ITune. There is a need for libraries to experiment with adding more information to the OPAC as well as pushing OPAC materials to the more popular search engines. Google Book provides links to holdings in a library when a hard copy is available there, and the "Library Search" in Google simultaneously searches WorldCat and 15 other union catalogs representing 30 countries (O'Leary, 2006). Many universities added libraries to their campus-wide portals to achieve "one stop shopping," and Byrum (2005a) predicted that the federated searching portal will ultimately serve as the library's principal web gateway to digital resources. Presently, users still need to go to different places to search for books and e-journal articles, and institutions are trying to unify the searches in the catalog, link resolvers and local collections. Users cannot gain a unified search experience when they need to find a paper map or a floor map somewhere else after they have found a record in the OPAC only to get lost in the maze of book stacks.

One way of improving the OPAC to meet the needs of the new generation of users is to integrate discovery tools, external web services and programming to the ILS. Commissioned by the Library of Congress (LC), Calhoun (2006) investigated the current status of the catalog, users, search engines and the scholarly information universe. She did structured interviews and wrote an extensive report on the integration of discovery tools into the ILS. In adding external discovery tools and web services to the OPAC, some of the efforts include North Carolina University Library's (NCSU, 2007) integration of the Endeca search engine into their ILS (Antelman et al., 2006), the US public libraries' bolting AquaBrowser on top of their ILS for better navigation (Queens, 2007), and Arkansas State University Library's test in adding a Google spell check to their OPAC (Crist and Farmer, 2007). NBAs (National Bibliographic Agencies) have been working on enriching the bibliographic records since the 1990s, and the efforts they took include extracting tables of contents (TOCs) from the manuscripts provided by publishers and adding them to the MARC records, adding sample excerpts and contributor information from the publisher supplied ONIX (Online Information Exchange) files to the OPAC, selecting annotations and reviews to be included in the OPAC, and linking bibliographic information to full-text electronic resources (Byrum, 2005b). Recently, libraries started to add cover images from Syndetic Solutions to the bibliographic record in the OPAC, and link the OPAC to tables of content, summaries and reviews provided by commercial companies such as Amazon (Buczynski, 2006). 
Presentation and visualization techniques are a supplementary way to transform the OPAC and augment user experience. New interfaces and new ways of presentation of information can be appealing. Some libraries, incorporated with companies, have experimented with integrating $2 \mathrm{D}$ and 3D to the OPAC. Aquabrowser, developed by Medialab Solutions, has been implemented in many public libraries in the US and its main feature is its concept maps, which can visualize the structure of the subject data (Kaizer and Hodge, 2005). Belmont Abbey College Library in North Carolina tried in 2003 to visualize cataloging surrogates and classification structures using VisualNet software from antarcti.ca systems (Beagle, 2003).

Under this broader context of the web's influence on user expectations and the library community's endeavor in transforming the OPAC by linking and integrating, interactive holding locations implemented at Wichita State University (WSU) Libraries aims to augment the user experience in locating library materials and enrich the OPAC by adding external programming into the ILS.

\section{Adding directional information to the OPAC}

Traditionally, libraries place signs on the different floors in the building and create floor maps for their collections. Directions are given on the floor, maps are put at the information desk and static digitized maps are to be found online at the library web site. Besides these common practices, many libraries have tried to add directional maps directly to the OPAC.

Some libraries add a label and a link on the results display page and direct users to an external web site for floor maps. For example, Worcester Polytechnic University Library's catalog provides in the search results page a "location" label which is linked to a list of locations and floor maps (George C. Gordon Library, 2007).

Linking a specific floor map rather than a list of maps from the search results page is not uncommon. The programs these libraries created for linking can find the relevant floor map based on the call number in the bibliographic record. For example, Auburn University Library Catalog provides a map logo linked to a corresponding floor map (AubieCat, 2007).

A few libraries can provide a certain level of dynamic location information to the users. They direct users from the OPAC to a specific floor map, which indicates the call number range the record falls in. They deal with the shelving situation in more detail, and they can specify call number range. They create different maps for different call number ranges. Their programs can pull out the relevant map based on the call number range.

"Dynamic" in dynamic mapping can mean different things in a directional map in a library. It can mean dynamically returning a location based on the query, or creating animated directional paths on a map, or it can also dynamically Wi-Fi (Wireless Fidelity) position the users.

Among the few libraries which achieved a certain level of "dynamic" in giving direction to collections, some libraries experimented with dynamicWi-Fi positioning of the user. In the SmartLibrary system at the University of Oulu in Finland, users can search the OPAC on a PDA (Personal Digital Assistants) and it can draw a route from the user's location to the floor where the item is located (Ekahau, 2003).

Some libraries provide both dynamic location information and dynamic visual presentation to the user on a certain level. The University of Huddersfield library catalog gives a floor map with a specific Dewey number range to each retrieved record (University of Huddersfield Library Catalog, 2007). They created the maps with $3 \mathrm{D}$ effect and an animated arrow directs the users to a Dewey number range.

The simple shelving situation is that all collections in a library are arranged by the same type of call number system. What if the collections are not only arranged by LC classification system, or Dewey, but also SuDoc (The Superintendent of Documents)?

How to deal with collections, which are placed in different libraries in a university, or different locations in a library? How to deal with electronic resources? WSU libraries' interactive holding location programming, also called dynamic mapping, can handle complicated shelving situations 
including a title with multiple copies shelved in different locations and/or in different formats, and it provides dynamic location information as well as animated directional paths to the users.

\section{Why develop interactive holding locations?}

Public Services personnel in a library always need to handle many directional questions. At WSU Libraries these questions can concern the building layout, the arrangement of collections on different floors, and the different rooms and areas for different types of services and materials, such as Reserve Desk, current periodical room and new book room. The main library, main stacks, special collection, and branch libraries are always confusing to the users too.

The shelving situations can be very complicated. At WSU Libraries, multiple classification schemes are used including LC, SUDOC, Accession Numbering, and local number; the same work can be in more than one location with different call numbers; Government Documents microforms are placed in one place, and other microforms in another, and CD/DVDs and their accompanying materials are shelved separately.

Current directional information in the OPAC is inadequate and not too user-friendly. Though traditional signage and floor maps exist, the incomprehensible call number and the long string of location explanation "Ablah(A-LC on Floor3)(LD-QR on Floor2)(R-ZA on LowerLevel)" are still hard for the users to interpret at WSU Libraries.

Some of the users just go to the stacks without reading the location, wandering from one floor to another and get frustrated. Many of the users do not bother to find the floor maps, as they are not directly linked to the record but in the OPAC right top menu along with "Ask a Librarian" and other links. The WSU OPAC Redesign Committee started to address these problems in 2006 using dynamic mapping, which gives dynamic location information in a visually appealing, animated way.

\section{Methodology}

The creation of dynamic mapping includes three steps. First, in order to display a more detailed map, the system should be able to capture the call number of a book found in a library catalog. Second, a programming logic needs to be created to handle complicated shelving situations. Third, the bibliographic data and holding data, such as description and location, should be displayed with the map to help the users to locate an item.

\section{Call number selection}

The methodology of dynamic map is displaying floor maps in accordance with LC classes. The first thing is to obtain a call number from a record in an OPAC. This page is usually displayed with bibliographic data, such as title, author and ISBN, and holding data, such as location, call number and availability for most of the ILSs. The way to display a dynamic map is similar to displaying a book cover image. Instead of sending an ISBN to the Syndetic or Amazon server, it should send a call number out for displaying a corresponding map.

Call numbers can be stored in several fields in a MARC record. For example, the LC call number is in MARC 050, GovDoc classification number is in MARC 086, and Local call number is in MARC 09X. For displaying a corresponding map correctly, the system has to receive all these call number fields and then find out the relevant call number among these fields. This makes it quite complicated.

Another dilemma is that it is possible for one bibliographic record to be attached to more than one holding record and with different call numbers. For instance, one copy of a book is shelved by its LC call number and another copy may be shelved in special collections with a local call number. It would be misleading to only display maps based on LC call numbers. The alternative is to display maps according to the call numbers in holding records. In that way, a bibliographic record with multiple call numbers will display multiple maps. However, is there a way to extract call numbers in holding records from an OPAC search results page?

As mentioned above, it is possible to transfer the bibliographic data, such as ISBN and call number, to another server. It is not easy to transfer the holding data, such as call number and location from 
an OPAC search results page. The alternative is to transfer a bibliographic record identifier instead of a call number, then query the database to get all necessary data for the map display through some connection utilities, such as ODBC (Open Database Connectivity), JDBC (Java Database Connectivity), DBI/DBD (DataBase Interface), etc.

\section{Programming logic}

After obtaining the necessary bibliographic and holding data from a database query outside of an OPAC search results page, a programming logic has to be established to handle complex shelving situations. Not all holdings are shelved by call numbers, or shelved in stacks location. For example, some locations, such as "Reserve", could be very small and not possible for a detailed map display; other locations, such as "Special Collections", have holdings that are not shelved by their call numbers. So, the first thing that needs to be considered is location. If a holding location is library stacks, the corresponding shelf map can be displayed. Otherwise, a location map will be displayed. Some books have copies in different formats. For example, a printed book may also have an electronic copy, on the internet or in multimedia format. Usually, the format information can be determined by its location, such as "E-Books" or by the link in the MARC 856 field. The program should be able to identify this situation, extract the links, and display the maps and links accordingly.

Many books come with accompanying CDs, DVDs, videocassettes, or audio recordings. For security reasons, in most libraries, these audio, data, or visual materials are separated from the books and shelved in the Reserve area. If maps only display the book location, patrons may not know they need to pick up accompanying materials somewhere else in the library until they check out the books. Therefore, the system should be able to find accompanying materials with the books and display the map locations for both books and accompanying materials.

For some historical reasons, the items are not always shelved in its holding location. These should be handled individually by the program to best reflect the current situation. Figure 1 shows a diagram of the data transfer and processing flow.

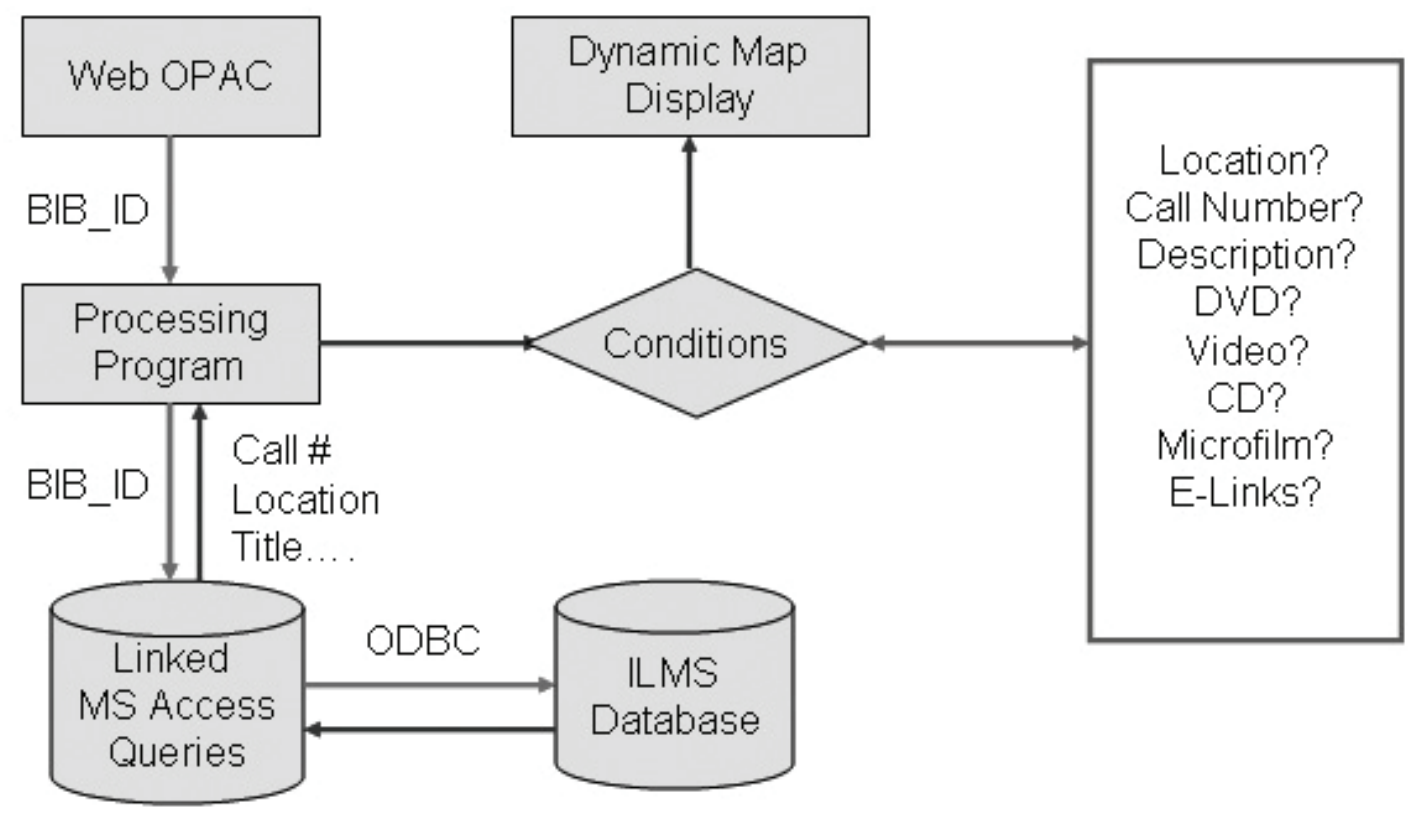

Figure 1.

Diagram of data processing flow 


\section{Map and description display}

After the data are processed by the program, the maps to be displayed for a specific search result are determined. The next step is to display the maps and accompanying fields. Maps are created for Locations and for LC class. Maps are animated GIF (Graphics Interchange Format) files and can be displayed quickly. The fields displayed with the maps are title, author, call number, location, description, electronic links, etc.All these elements are formatted and displayed in a server-side dynamic page.

\section{Results}

The methodology of dynamic map display has been first applied to Wichita State University Libraries catalog in its OPAC redesign project. It achieved great success in providing patrons with accurate and more detailed shelving information. Compared to title-level shelving map displays that have been implemented in some libraries, holding level map displays solve the problem of complex shelving situations. The results of dynamic map display are listed below.

. multiple maps are displayed for holdings at different locations. For example, a book published long ago with more than one copy in the libraries could be available in multiple library locations; one copy may be in the library stacks and another could be in special collections. The routine will display both maps as item 1 and item 2 (see Figure 2);

Title :

West of Wichita : settling the high plains of Kansas, 1865-1890/

Author :

Call \# :

ITEM 1

:

F686 ,M56 1986

Location :

Description:

Ablah(A-LC on Floor3)(LD-QE on Floor2)(QH-ZA on LowerLevel)

viii, 303 p. : ill. ;24 cm.

Map:

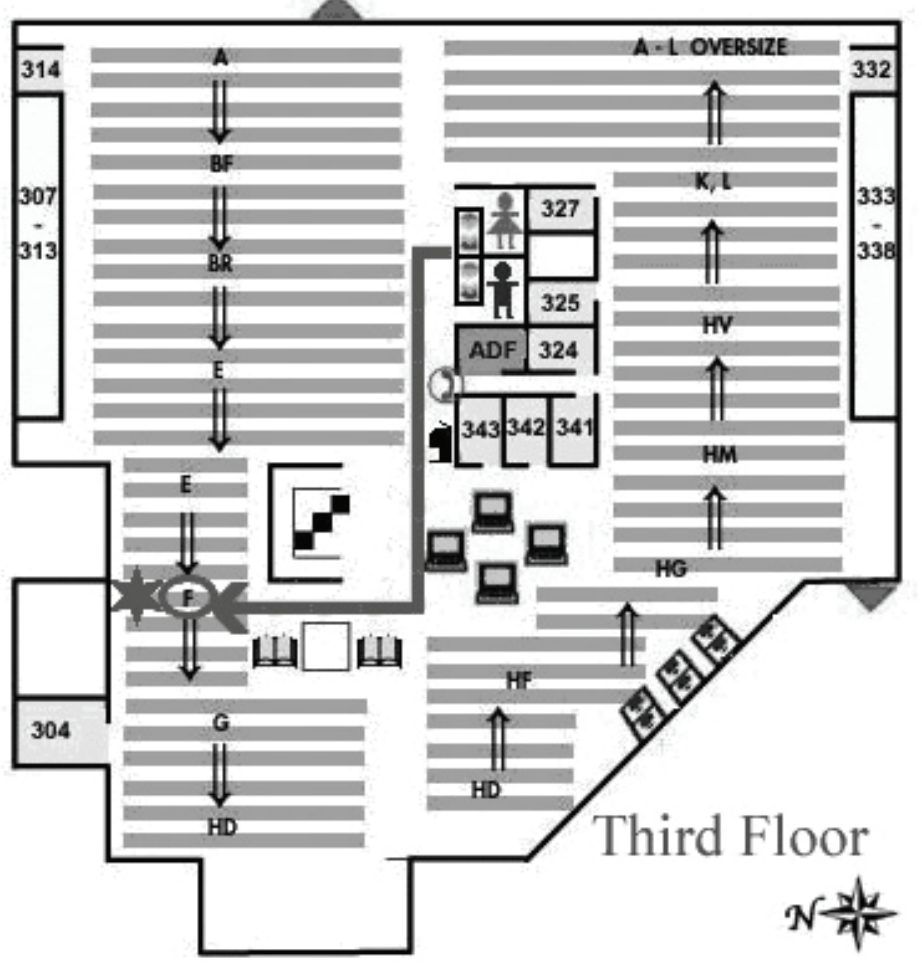



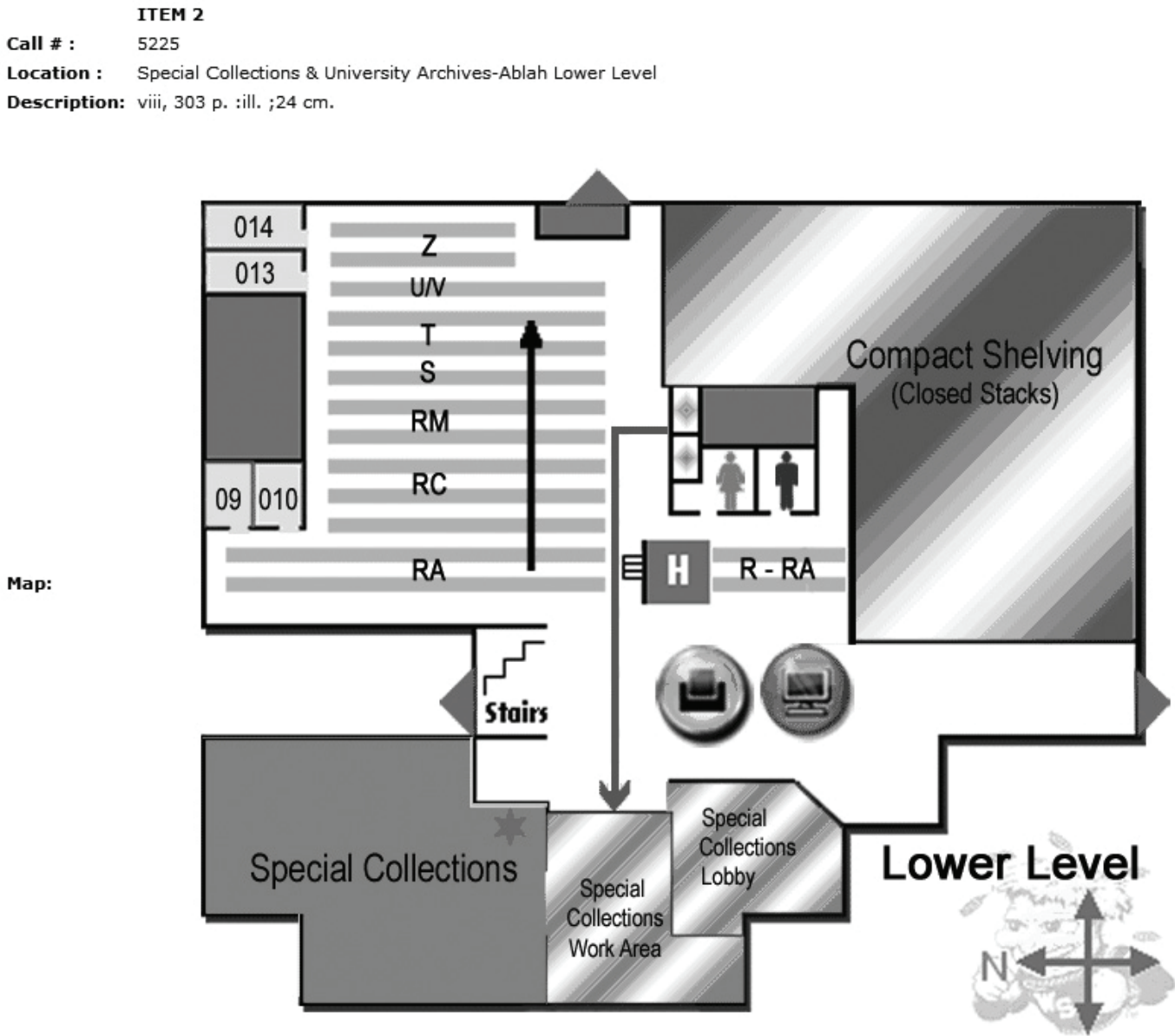

Figure 2.

Multiple maps displayed for different locations in OPAC at WSU libraries

. multiple maps are displayed for holdings in different formats. For example, a book with both printed and electronic formats will be displayed separately. A map is displayed for the printed copy, and a link connecting to the online resource is displayed for the electronic copy;

. for some books with the same broad LC class, but shelved on different floors, the routine will select maps based on its second detailed LC class. The routine then decides which floor map should be displayed for this holding record;

. the accompanying material data is in the 300 field in MARC record. The routine puts the 300 field received from the OPAC record display page into a variable. If the variable contains DVD, video, or audio strings, the second map of the Reserve location will be displayed for these accompanying multimedia materials;

. branch libraries do not have floor or shelf maps. When materials in these branch libraries are identified based on holdings location, instead of a location map, a campus map showing the route from the main library to these branch libraries;

. some of the holdings in Wichita State University Libraries catalog belong to an affiliated organization in the city. These holdings can be identified by their holdings location too. In this scenario, an embedded Google direction map would be displayed by employing Google API (Application Programming Interface); and 
. some materials in special formats, such as microfilm, used to be shelved in library stacks, but are now changed to Microfilm area. Although the holding location is still library stack, the processing routine checks the string in holding call number which starts with "Microfilm" and displays the location map based on that string instead of the LC class.

The examples can be found at: http://library.wichita.edu/techserv/dynamicmap.html

\section{Implementation}

The implementation of dynamic map can be done in many ways. It depends on the ILS system a library uses. The method developed in Wichita State University Libraries catalog with the Voyager system can be applied to any ILS as long as the system database can be accessed through a database interface driver, such as ODBC. The following are the key points for implementing dynamic map in a library OPAC.

. transferring bibliographic ID number from a search results page to a processing routine. At Wichita State University Libraries, the syntax in the OPAC configuration file for sending ISBN to Syndetic is something like "HTML:020ka: $\{\mathrm{a}\}$ ". This can be replaced by "HTML:001ka: $\{\mathrm{a}\}$ " for sending Bibliographic ID instead of ISBN. The similar methods should be used in other ILSs. The syntax may be varied; the principle should be the same;

. processing routine development. An active server page was created for receiving data from a search result and to deal with various complex-shelving situations. The page is hosted in a Windows 2003 server with an ODBC connection to the ILS database. The data extraction and map display are controlled by the script in the ASP (Active Server Pages) page. This is not the only solution for establishing the processing routine. There are quite a few alternatives that can be used in different platforms to perform the same tasks, as long as connections to ILS databases can be established; and

. maps creation and display. A variety of graphic and animation software can be used to create dynamic maps. At WSU libraries, the maps were created originally using Adobe Photoshop and ImageReady. The floor maps were made with Photoshop 7.0 and the animated directional paths were made with ImageReady 7.0. Later, the updated maps were created using Adobe Photoshop CS2 and ImageReady CS2.

\section{Discussion/issues arising}

WSU's dynamic mapping project was first brought to the Voyager user community in its last EndUser Conference in 2007. The session was very popular and many requests for releasing the mapping code were received. Since then, it has been a hot topic and many discussions have been raised. These are a few perspectives that engaged the discussion:

\section{Map display options}

There are several options on how to display the maps on the search results page:

. to display maps directly on the search results page. The advantage of this approach is that it is obvious and it does not require the user's additional clicks, and the disadvantage is that the search results page will become very long; . to display thumbnails directly on the search results page. It takes extra clicks but it brings more attentions to the users than a simple link; and

. the label "map direction" linked to external directional maps. This approach has been practiced by most libraries.

\section{The mapping code}

The mapping code was written in ASP at WSU Libraries. It can be converted to PHP (Hypertext Preprocessor) or PERL (Practical Extraction and Report Language), used in UNIX-like systems. 


\section{The format of the map files}

The map can be in any format, theoretically. Though it is not necessary to add animation to the maps, it always catches the users' eyes if the maps are animated. Future possibilities include creating the maps in 3D and displaying the maps based on the user's current location.

\section{How to deal with shelving locations change?}

Shelving locations change is not unusual in most libraries. The maps need to be updated to reflect the most current shelving situation. Either the image files needed to be updated to reflect the location change or the dynamic mapping program needs to be modified. For example, due to the compact shelving project at WSU Libraries, large volumes of materials were shifted; we modified the map files, which indicate the call numbers ranges, and added new locations such as Wichita Art Museum (to whom we are under contract) to the mapping program.

\section{Conclusion}

Providing interactive holding location information through dynamic mapping can augment user experiences in discovering and locating materials in an OPAC. While providing directional information for library materials is not new, to present this information at the item level in a dynamic way is still novel. This article discussed the broader context of linking and integration. The origin of dynamic mapping, its methodology and implementation, is not specific to a particular ILS system. It can be applied to different ILS systems in various libraries. Future possibilities include combining other technologies, such as Wi-Fi positioning of the users, RFID (Radio-frequency identification), virtual shelves and 3D animation, with dynamic mapping of holding locations to the animated maps in an OPAC.

\section{References}

Antelman, K., Lynema, E. and Pace, A.K. (2006), "Toward a 21st century library catalog", Information Technology and Libraries, Vol. 25 No. 3, pp. 128-39.

AubieCat (2007), Intro: Auburn University Libraries' Catalog, available at: http://aubiecat. auburn.edu (retrieved August 1).

Beagle, D. (2003), "Visualizing keyword distribution across multidisciplinary C-space", $D$ LibMagazine, Vol. 9 No. 6.

Buczynski, J.A. (2006), "New metadata expectations: moving beyond the card catalog paradigm", Internet Reference Services Quarterly, Vol. 11 No. 1, pp. 107-11.

Byrum, J.D. (2005a), "Online catalogs and library portals in today's information environment", Journal of Library Administration, Vol. 43 Nos 1/2, pp. 135-54.

Byrum, J.D. (2005b), "Recommendations for urgently needed improvement of OPAC and the role of the National Bibliographic agency in achieving it", paper prepared for the 71st IFLA General Conference and Council, Oslo, August 14-18, available: www.ifla.org/IV/ifla71/ papers/124e-Byrum.pdf

Calhoun, K. (2006) in Calhoun, K. (Ed.), The Changing Nature of the Catalog and its Integration with Other Discovery Tools, K. Calhoun, Ithaca, NY, available at: www.loc.gov/catdir/calhounreport-final.pdf

Crist, W. and Farmer, T. (2007), "Enhancing WebVoyage using Google APIs", Conference Proceedings: Voyager EndUser 2007, Schaumburg, IL.

DeRosa, C. (2005), Perceptions of Libraries and Information Resources, available at: www.oclc.org/reports/2005perceptions.htm

Dempsey, L. (2006), "The library catalogue in the new discovery environment: some thoughts", Ariadne, Vol. 48, available at: www.ariadne.ac.uk/issue48/dempsey/

Ekahau (2003), "Enables location-aware library navigation system”, Advanced Technology

Libraries, Vol. 32 No. 8, p. 3. 
George C. Gordon Library (2007), WPI George C. Gordon Library [Catalog], available at: http://library.wpi.edu/cgi-bin/Pwebrecon.cgi?DB 1/4 local\&PAGE 1/4 First (retrieved August 1). Kaizer, J. and Hodge, A. (2005), “AquaBrowser library: search, discover, refine”, Library Hi TechNews.

NCSU Catalog (2007), "North Carolina state university libraries catalog", available at: www.lib. ncsu.edu/catalog/ (retrieved August 1).

O’Leary, M. (2006), "Google book search has far to go", Information Today, Vol. 47, November. Queens (2007), "Other libraries utilize new Aquabrowser features", Advanced Technology Libraries, Vol. 35 4, April.

University of Huddersfield (2007), "University of Huddersfield library catalog", available at: wwwcls.hud.ac.uk/cls-bin/cls.pl?c 1/4 24/18/19 (retrieved August 1).

\section{About the authors}

Hongfei Li used to be the Systems Developer at Wichita State University Libraries, and he currently works as a Systems Librarian at City University in Seattle. He is the corresponding author and can be contacted at: hongfeili@cityu.edu

Sai Deng is a Metadata Cataloger Librarian at Wichita State University Libraries.

To purchase reprints of this article please e-mail: reprints@emeraldinsight.com Or visit our web site for further details: www.emeraldinsight.com/reprints 